\title{
PEMBANGUNAN SISTEM INFORMASI POSYANDU DI KECAMATAN SINDANG KABUPATEN INDRAMAYU (Studi Kasus : Posyandu Mawar Desa Panyindangan Wetan)
}

\author{
Stephanie Betha Rossi $\mathbf{H}^{\mathbf{1}}$, Bakhrul Ullum ${ }^{2}$ \\ ${ }^{1}$ Fakultas Teknik Universitas Wiralodra Indramayu, ${ }^{2}$ AMIK Purnama Niaga Indramayu. \\ 므tephbetha@gmail.com, ${ }^{2}$ bakhrul96@gmail.com
}

\begin{abstract}
ABSTRAK
Posyandu Mawar merupakan suatu unit layanan kesehatan yang bertugas untuk melakukan pelayanan kesehatan ibu dan anak (KIA) di wilayah RW 02 Desa Panyindangan Wetan Kecamatan Sindang Kabupaten Indramayu. Saat ini, proses manajemen data di Posyandu Mawar masih dilakukan secara manual dengan cara mencatatkan data ke dalam tujuh (7) format register. Cara tersebut dinilai tidak efisien karena menyebabkan kesulitan dalam proses manajemen data Posyandu Mawar. Untuk mengatasi permasalahan tersebut, maka penulis bermaksud mengembangkan suatu sistem informasi posyandu berbasis web dengan menggunakan bahasa pemograman PHP dan MySQL sebagai sistem manajemen basis data. Pengumpulan data dilakukan dengan cara observasi dan wawancara. Metode pengembangan sistem yang digunakan adalah metode terstruktur. Alat yang digunakan dalam analisis dan perancangan sistem adalah Flow Of Diagram (FOD), Diagram Arus Data, Entity Relationship Diagram (ERD), Desain InputOutput sehingga menghasilkan suatu aplikasi yang terpadu. Hasil dari penelitian ini adalah aplikasi pengolahan data posyandu yang dapat membantu pihak Posyandu Mawar dalam melaporkan kegiatan pelayanan terhadap bayi dan ibu hamil. Pada pengembangan selanjutnya, diharapkan sistem informasi posyandu ini dilengkapi dengan fitur grafik pita KMS untuk memantau perkembangan berat badan anak.
\end{abstract}

Kata Kunci : Sistem Informasi Posyandu, PHP, MySQL, KMS.

\begin{abstract}
Posyandu Mawar is a health service unit that is tasked with carrying out maternal and child health services (KIA) in the RW 02 Panyindangan Wetan Village, Sindang District, Indramayu Regency. At present, the data management process in Mawar Posyandu is still done manually by recording data into seven (7) register formats. This method is considered inefficient because it causes difficulties in the Posyandu Mawar data management process. To overcome these problems, the authors intend to develop a web-based posyandu information system using PHP as a programming language and MYSQL as a database management system. Data collection is done by observation and interview. The system development method used is a structured method. The tools used in system analysis and design are Flow Of Diagrams (FOD), Data Flow Diagrams, Data Dictionaries, Entity Relationship Diagrams (ERD) so as to produce an integrated application. The results of this study are posyandu data processing applications that can help Posyandu Mawar in reporting service activities to infants and pregnant women. In subsequent developments, it is expected that the posyandu information system is equipped with KMS ribbon chart features to monitor the child's weight development.
\end{abstract}

Keyword : $\quad$ Posyandu Information System, PHP, MySQL, KMS. 


\section{PENDAHULUAN}

Posyandu Mawar merupakan suatu unit layanan kesehatan dibawah naungan Dinas Kesehatan Kab. Indramayu yang berada di wilayah RW 02 Desa Panyindangan Wetan Kec. Sindang Kab. Indramayu. Posyandu bertugas untuk melakukan kegiatan pelayanan kesehatan berbasis masyarakat berupa pelayanan Kesehatan Ibu dan Anak (KIA).

Seluruh kegiatan Posyandu Mawar dicatatkan ke dalam Sistem Informasi Posyandu. Proses pencatatan dan pengolahan data masih dilakukan secara manual menggunakan tulisan tangan sehingga menyebabkan banyak kendala dalam proses pengolahan, pencarian, dan pembuatan laporan kegiatan Posyandu Mawar.

Sistem Informasi Posyandu yang berjalan di Posyandu Mawar saat ini bersifat manual, dimana pencatatan masih menggunakan tulisan tangan sehingga kader kesulitan dalam pemantauan tumbuh kembang anak dan kesulitan dalam pembuatan laporan kepada pembina posyandu atau pun pokja TP PKK. Karena sulitnya proses pengolahan data, maka kader posyandu terkadang melakukan kesalahan dalam penghitungan data saat pembuatan laporan kegiatan Posyandu Mawar sehingga laporan yang dihasilkan tidak tepat dan akurat. Oleh sebab itu, kader posyandu merasa cara tersebut dianggap tidak efisien baik dari segi tenaga maupun waktu.

Berdasarkan permasalahan yang terjadi di Posyandu Mawar, maka penulis bermaksud mengembangkan suatu sistem informasi posyandu berbasis web untuk memudahkan proses pengolahan, pencarian, dan pelaporan data kegiatan Posyandu Mawar.

\section{METODOLOGI PENELITIAN}

\section{Posyandu}

Posyandu adalah singkatan dari Pos Pelayanan Terpadu yang merupakan suatu wadah komunikasi alih teknologi dalam pelayanan kesehatan masyarakat dari masyarakat, oleh masyarakat dan untuk masyarakat dengan dukungan pelayanan serta pembinaan teknis dari petugas kesehatan dan keluarga berencana [2].

\section{Sistem Informasi Posyandu}

Sistem Informasi Posyandu (SIP) atau yang lebih dikenal sebagai Buku Register Kader adalah rangkaian kegiatan untuk menghasilkan informasi yang sesuai dengan kebutuhan secara tepat guna dan tepat waktu bagi pengelola Posyandu. [2]

Sistem Informasi Posyandu merupakan bagian penting dari pembinaan Posyandu secara keseluruhan. Pembinaan akan lebih terarah apabila didasarkan pada informasi yang lengkap, akurat dan aktual. Dengan kata lain, pembinaan merupakan jalan keluar dari permasalahan yang dihadapi karena didasarkan pada informasi yang tepat, baik dalam lingkup terbatas maupun lingkup yang lebih luas. [2]

\section{Flow of Document (FOD)}

Flow of Document (FOD) atau adalah diagram yang menunjukan arus data dari dokumen yang mengalir dari proses awal sampai akhir. [3]

\section{Diagram Arus Data (DAD)}

Data Flow Diagram atau Diagram Arus Data adalah model dari sistem untuk menggambarkan pembagian sistem ke modul yang lebih kecil. Adapun tahapan-tahapan perancangan dengan menggunakan DAD adalah sebagai berikut [1] :

a. Diagram konteks (Context Diagram)

Diagram konteks menunjukkan semua proses bisnis dalam satu proses tunggal (proses 0). Diagram konteks juga menunjukkan semua entitas luar yang memberikan informasi ke sistem atau menerima informasi dari sistem.

b. Diagram Rinci (Level Diagram)

Diagram rinci adalah diagram yang menguraikan proses yang ada dalam zero diagram.

\section{Entity Relatinship Diagram (ERD)}

Entity Relatinship Diagram merupakan teknik yang digunakan untuk memodelkan kebutuhan data dari suatu organisasi, biasanya oleh sistem analisis dan tahap analisis persyaratan proyek pengembangan sistem. Sementara seolah-olah teknik diagram atau alat peraga memberikan dasar untuk desain database rasional yang mendasari sistem informasi yang dikembangkan. [4]. 


\section{HASIL DAN PEMBAHASAN}

\section{A. Sistem Yang Sedang Berjalan}

Alur kerja dari sistem informasi posyandu yang sedang berjalan adalah kader posyandu mencatatkan seluruh data layanan kesehatan ibu dan anak yang telah dilakukan ke dalam SIP. Setelah itu, kader posyandu membuat laporan kegiatan posyandu dengan cara mengelompokkan data kegiatan posyandu yang ada dalam SIP berdasarkan pelayanan kesehatan yang diberikan, misalnya penimbangan berat badan, imunisasi, pemberian vitamin $\mathrm{A}$, dan sebagainya.

Setelah laporan selesai dibuat, kemudian laporan digandakan dan diserahkan kepada Pokja IV TP PKK, pembina posyandu dan petugas kesehatan.

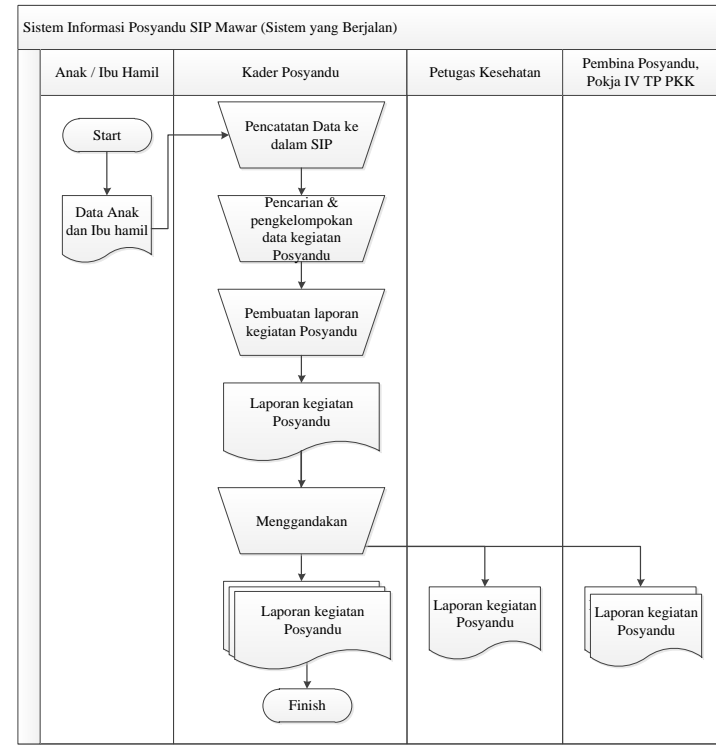

Gambar 1. Alur Kerja Sistem Berjalan

\section{B. Sistem Yang Diusulkan}

Berdasarkan hasil analisa yang telah dilakukan, maka penulis mengusulkan sebuah sistem yang dapat mengatasi permasalahan pada SIP yang berjalan saat ini. Usulan sistem yang dimaksud adalah dengan mengembangkan sebuah sistem informasi berbasis web yang dapat mengolah, menyimpan, dan mencari data-data kegiatan Posyandu Mawar sehingga dapat menghasilkan informasi dalam bentuk laporan yang dibutuhkan oleh pihak-pihak terkait. Berikut ini adalah rancangan penulis dalam membuat desain sistem yang diusulkan berdasarkan sistem yang berjalan

\section{a. Flow of Document (FOD) yang diusulkan}

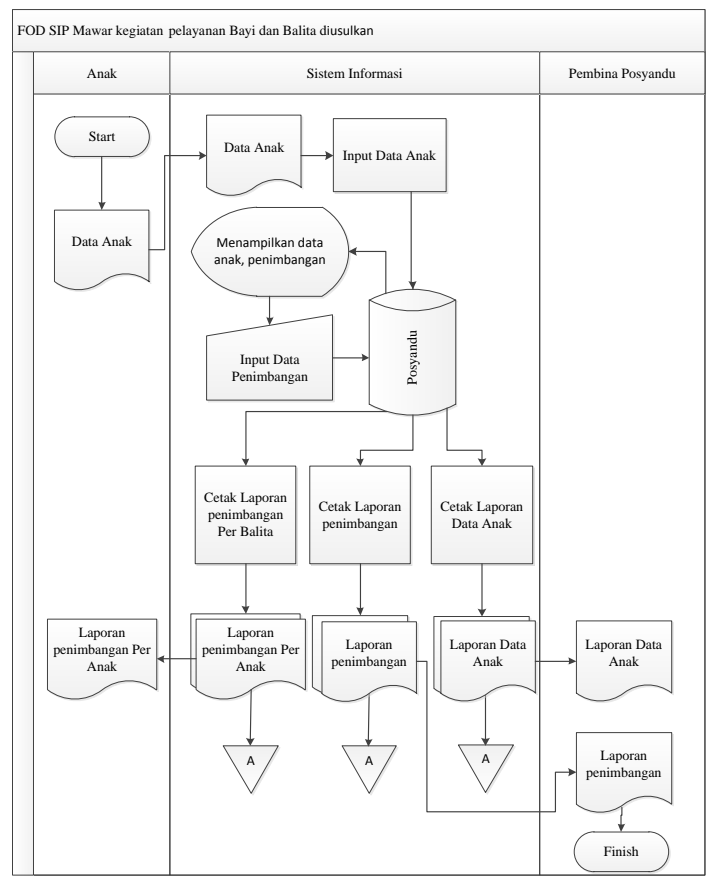

Gambar 2. FOD Pelayanan Anak Diusulkan

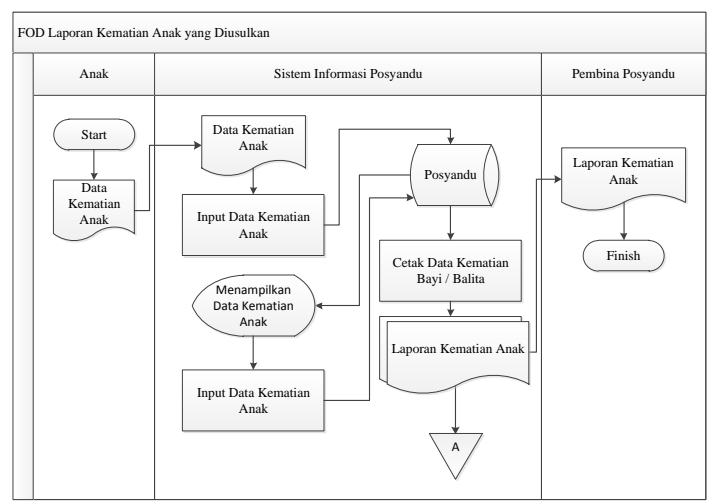

Gambar 3. FOD Laporan Kematian Anak

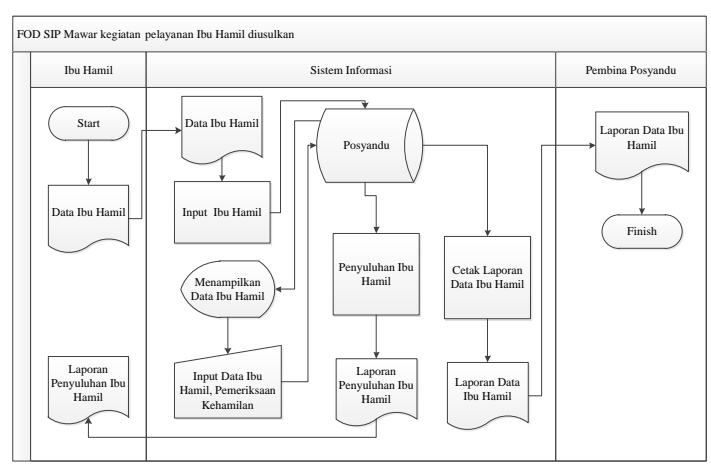

Gambar 4. FOD Pelayanan Ibu Hamil 


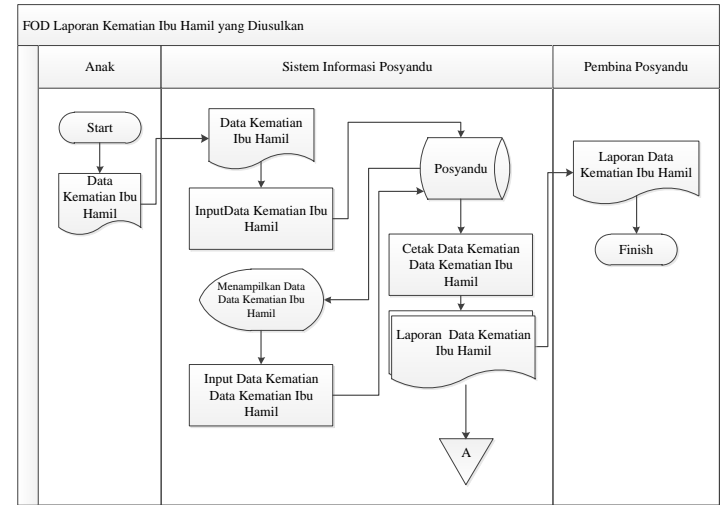

Gambar 5. FOD Laporan Kematian Ibu Hamil

\section{b. Diagram Arus Data (DAD)}

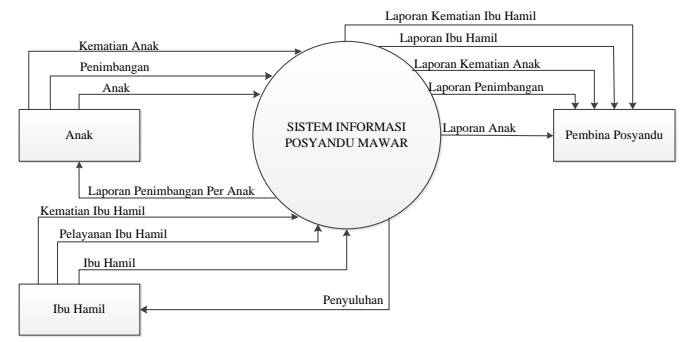

Gambar 6. Diagram Konteks

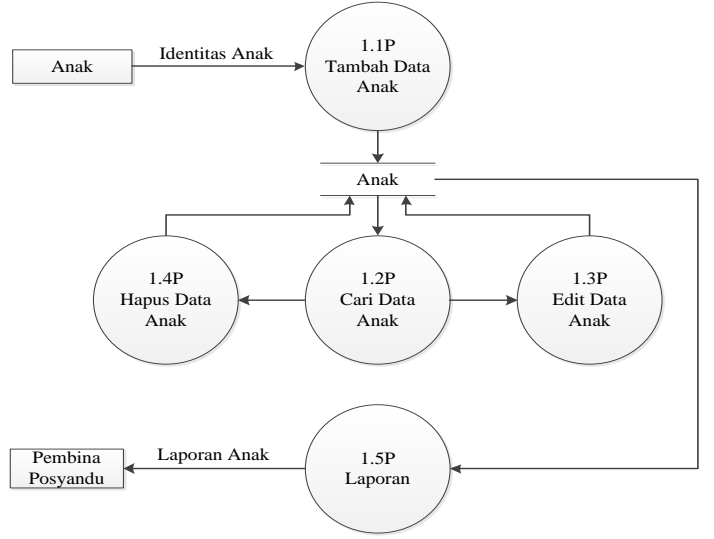

Gambar 7. DAD Mengolah Data Anak

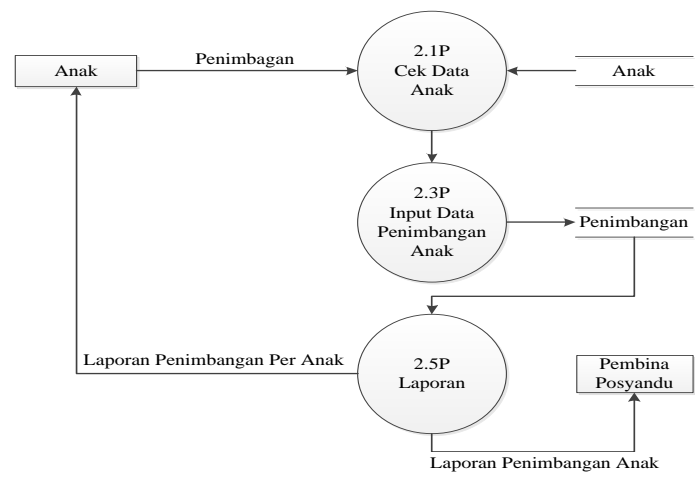

Gambar 8. DAD Mengolah Data Penimbangan Anak

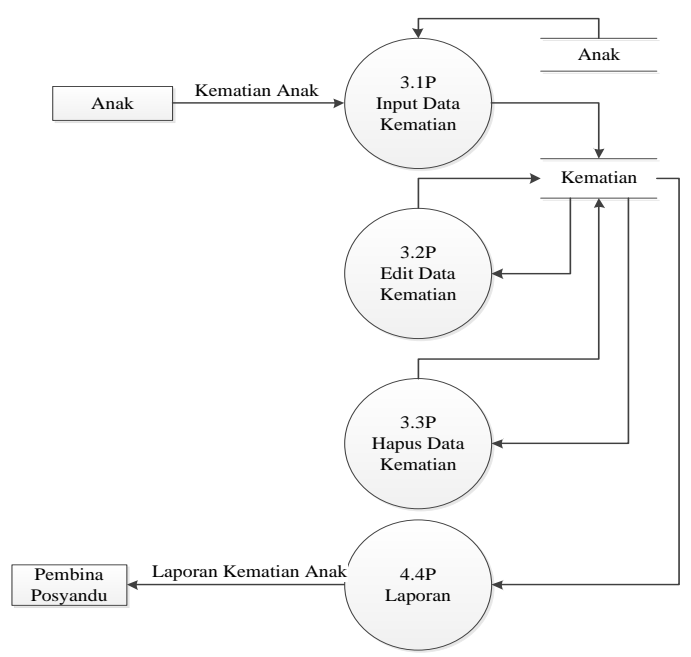

Gambar 9. DAD Mengolah Data Kematian Anak

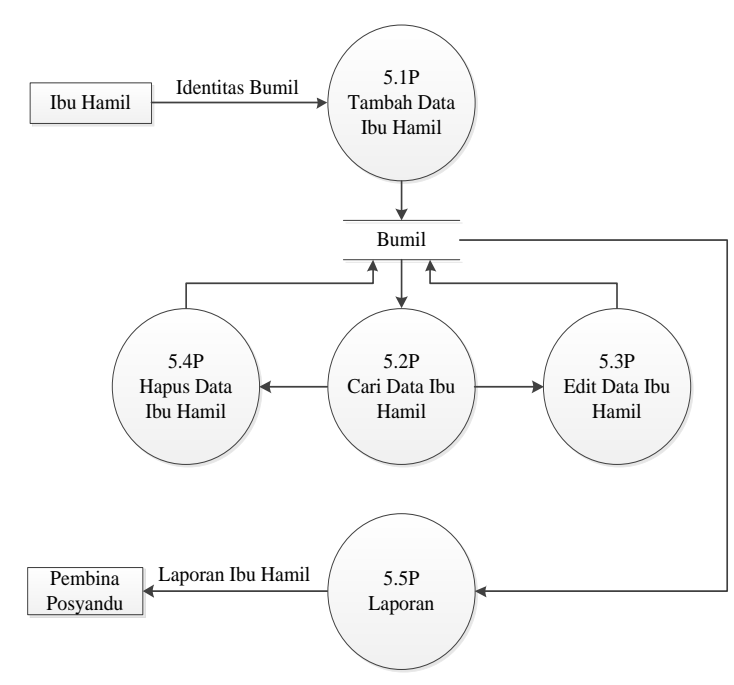

Gambar 10. DAD Mengolah Data Ibu Hamil

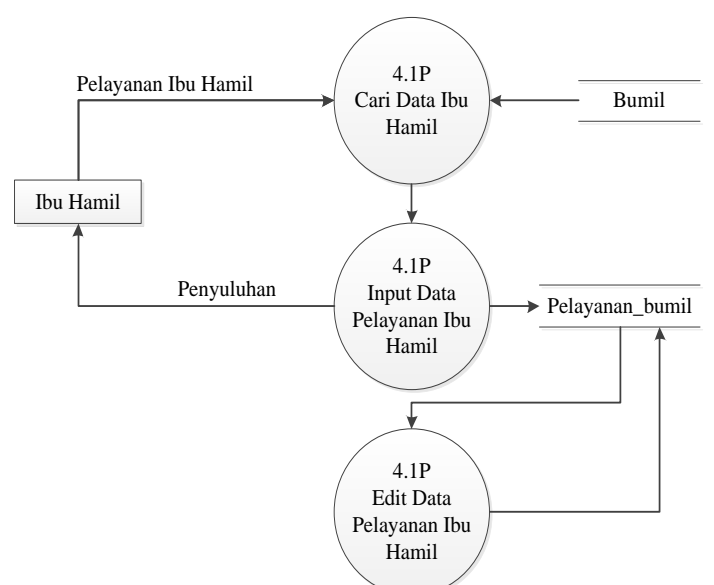

Gambar 11. DAD Pelayanan Ibu Hamil 


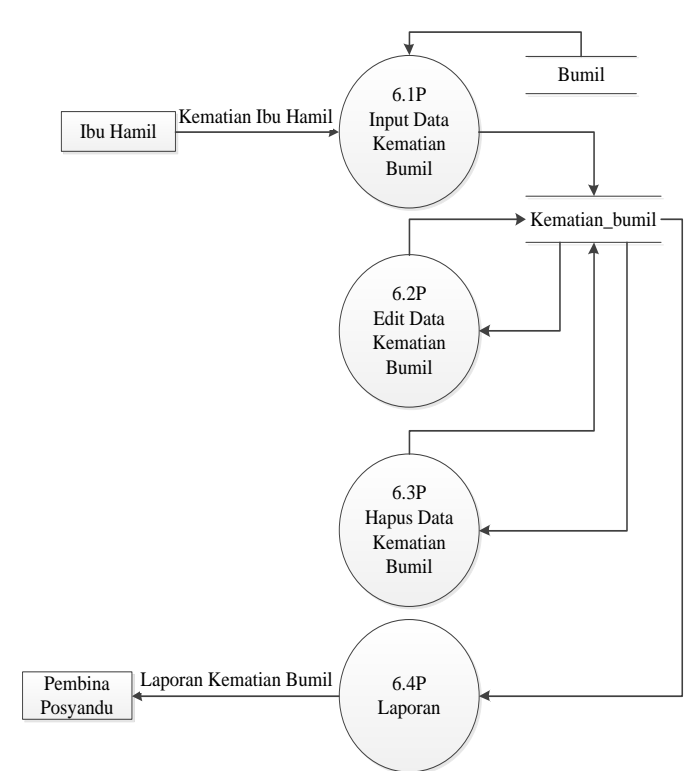

Gambar 12. DAD Kematian Ibu Hamil

\section{c. Entity Relationship Diagram (ERD)}

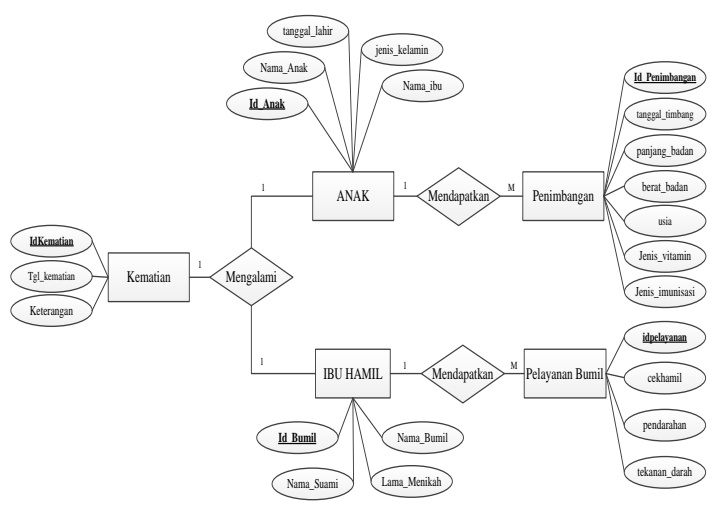

Gambar 13. ERD Posyandu Mawar

\section{KESIMPULAN}

Perancangan Sistem Informasi Posyandu merupakan pengembangan dari sistem yang sedang berjalan. Berdasarkan uraian dari penjelasan yang telah dikemukakan pada bab-bab sebelumnya maka penulis dapat mengambil kesimpulan bahwa sistem Informasi Posyandu Mawar yang sedang berjalan masih menggunakan sistem manual sehingga mengakibatkan pelayanan masih kurang optimal, oleh karena itu dengan sistem baru yang dibuat diharapkan dapat mendukung pembenahan pelayana di Posyandu Mawar menjadi lebih baik. Dalam penelitian ini, dimana perancangan sistem tersebut meliputi :

1. Fitur pengolahan dan penyimpanan data yang disesuaikan dengan kebutuhan pihak Posyandu Mawar maka data kegiatan Posyandu Mawar menjadi lebih mudah untuk diolah dan diakses kembali.

2. Fitur pembuatan laporan dapat membantu pihak Posyandu Mawar dalam memperoleh informasi kesehatan anak.

\section{DAFTAR PUSTAKA}

[1] Brady, M., \& Loonam, J. (2010). Exploring the use of entity-relationship diagramming as a technique to support grounded theory inquiry. Bradford: Emerald Group.

[2] Jogiyanto H.M.1997. Sistem Informasi Berbasis Komputer Konsep Dasar dan Komponen. BPFE-Yogyakarta: Yogyakarta.

[3] Ladjamudin, Albahra. 2005. Analisis dan Desain Sistem Informasi. Graha Ilmu:Yogyakarta.

[4] Sembiring, Nasap. 2004. Posyandu Sebagai Saran Peran Serta Masyarakat Dalam Usaha Peningkatan Kesehatan Masyarakat.

http://library.usu.ac.id/download/fkm/bi ostatistik-nasap.pdf (18 Juli 2018) 
